\title{
Study on Concrete Containing Recycled Aggregates Immersed in Epoxy Resin
}

\author{
Suraya Hani Adnan ${ }^{1}$, Alshrif Abdslam Alsonosi ${ }^{2}$, Suzana Wati Adnan ${ }^{3}$ \\ ${ }^{1}$ Faculty of Engineering Technology ${ }^{1}$,Universiti Tun Hussein Onn Malaysia, Malaysia \\ ${ }^{2}$ Faculty of Civil and Environmental Engineering, Universiti Tun Hussein Onn Malaysia, Malaysia \\ ${ }^{3}$ Civil Engineering Department, Polytechnic Kuching Sarawak, Malaysia
}

\begin{abstract}
In recent decades, engineers have sought a more sustainable method to dispose of concrete construction and demolition waste. One solution is to crush this waste concrete into a usable gradation for new concrete mixes. This not only reduces the amount of waste entering landfills but also alleviates the burden on existing sources of quality natural concrete aggregates. There are too many kinds of waste but here constructions waste will be the priority target that should be solved .It could be managed by several ways such as recycling and reusing the concrete components, and the best choice of these components is the aggregate, because of the ease process of recycle it. In addition, recycled aggregates and normal aggregates were immersed in epoxy resin and put in concrete mixtures with $0 \%, 5 \%, 10 \%$ and $20 \%$ which affected the concrete mixtures properties. The strength of the concrete for both normal and recycled aggregates has increased after immersed the aggregates in epoxy resin. The percentage of water absorption and the coefficient of water permeability decreased with the increasing of the normal and the recycled aggregates immersed in epoxy resin. Generally the tests which have been conducted to the concrete mixtures have a significant results after using the epoxy resin with both normal and recycled aggregates.
\end{abstract}

\section{Introduction}

Recycled Aggregate (RA) can be defined as an aggregate that has been produced from used material as coarse or fine aggregate. RA can be produced from different sources like broken precast elements and cubes after testing, and demolished concrete buildings (Rao et al., 2007). Olorunsogo \& Padayachee (2002) revealed that RA consisting materials like dust, mortar, brick, stone and mortar. In RA, the lowest percentage of proportion is dust which accounted $1.90 \%$ and the highest proportion is stone and mortar which is $84.60 \%$ (Olorunsogo \& Padayachee, 2002). RA can be produced from large amount of waste material from construction industry which this waste material can lead into environmental problem. Thus, Ravindrarajah (1987), Adnan et al. (2007) and Abdel-Hay (2015) expressed their opinions that using RA would reduce the use of natural aggregate and landfill for disposal.

Nowadays the whole world focus on reducing the constructions and demolition waste that will affect our environment and the sustainability due to the principle of sustainable construction must prudent the natural resources and encourage this approach in all government activities (Cakir and Sofyanh, 2015) .

"Construction waste" means any substance, matter or thing which is generated as a result of construction work and abandoned. It is a mixture of surplus materials arising from site clearance, excavation, construction, refurbishment, renovation, demolition and road works.

Over $90 \%$ of construction waste are inert and are known as public fill. Public fill includes debris, rubble, earth and concrete which is suitable for land reclamation and site formation. If they just separate certain materials such as concrete and asphalt these materials can be used again or recycled for constructions usages.
Approximately 110 million tonnes of construction, demolition and excavation waste (C\&DW) are generated in UK yearly, accounting for over $60 \%$ of the country's total waste. Increasing interest in RA application is because the increasing cost of landfill, anxiety of decreasing in natural resources and increasing in aggregate requirement for construction work (Khatib, 2005).

One of the main wastes produced by constructions is unused concrete like beams and columns which is produced by demolition process and also concrete cube produced from the concrete tests. Hence, for sustainable purpose all those unused concrete could be recycle or reuse so that the consumption of natural resources could be reduce. Concrete could be useful by reusing its aggregates instead of dispose .There are too many reasons to reuse the recycled aggregate such as conservation of our environment and sustainability and economic reasons .Recycling is the process of reusing materials for further use to develop new product. It includes the breaking of concrete to produce smaller size of fragments .Hence, this study is conducted to determine the properties of recycled aggregate concrete which using the aggregate that has been immersed in epoxy resin.

Epoxy resins are generally recognized as workhorse products among the category of thermosetting polymers due to their outstanding mechanical properties and good handling characteristic. The use of epoxy resins in industry extends back over fifty years since their introduction commercially and they find an extremely wide range of applications as coatings, adhesives and matrix resins in different fields $G$ like electronics, defense, aerospace industry etc. The main advantages of epoxy resins are their good mechanical properties, minimum shrinkage after cure and suitable weather, 
chemical and electrical resistace (Gilat et al, 2007 and $\mathrm{Li}$ et al., 2015).

\section{Materials and Methods}

\subsection{Materials}

The materials that have used in this study are cement, recycled aggregates, normal aggregates, resin to immerse the recycled aggregates and the normal aggregates on it, water and the sand.The source for recycled aggregates is the waste cubes from the Laboratory of Concrete in Universiti Tun Hussein Onn Malaysia (UTHM).

\subsection{Epoxy Resin}

Epoxy resins have a wide variation in properties. Consequently, it is possible to formulate many different compound with each compound having slightly different characteristics. As in example of the range of properties that an epoxy resin may have, it is possible for an epoxy to be as brittle as glass or as mobile as water. Hence, for this study Epoxy Resin has been used as a water resistance by immersing both the normal and the recycled aggregates on it. Figure 1 illustrated the normal and recycled aggregates immersed in various percentage of resin $(0,5,10$ and 20$)$.

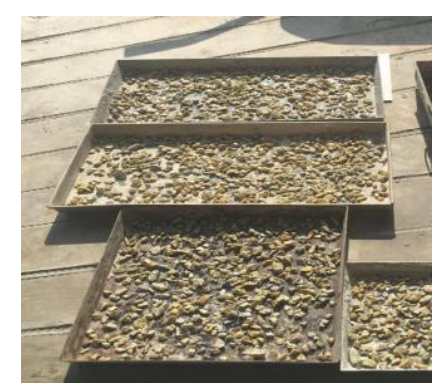

Figure 1. Normal and recycled aggregates immersed in resin

\subsection{Aggregate}

Fine aggregates and coarse aggregates have been used in this study for producing the concrete specimens. According to Neville (2012) the size of fine aggregates were the aggregates which passed through the sieve 4.75 $\mathrm{mm}$. Two types of coarse aggregate that have been used in this study are Normal Aggregates (NA) and the Recycled Aggregates (RA). Recycled Aggregates (RA) is as shown in Figure 2. The normal and the recycled aggregates were place in the room temperature for 24 hours after immersed in the resin in order to dry well and take the same shape with the aggregate. The size for coarse aggregates that have used in this study is between $(5 \mathrm{~mm}-20 \mathrm{~mm})$.

\subsubsection{Aggregate Test}

In this studyt there are several tests that have been conducted for the aggregates before concrete were cast such as Aggregates Impact Value (AIV) Test and Aggregates Crushing Value (ACV) Test. The aim for these tests is to assess the physical properties of the aggregates that have used in this study which are normal aggregates, recycled aggregates, normal aggregates immersed in resin and recycled aggregates immersed in resin.

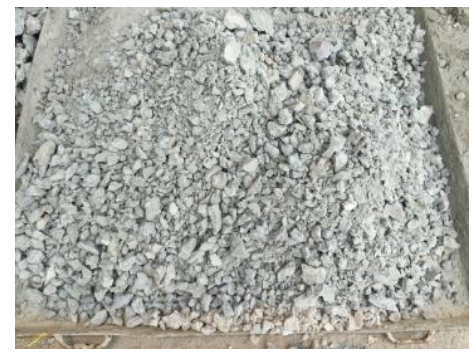

Figure 2. Recycled Aggregates (RA)

\subsection{Concrete Mix Design}

For this study, the concrete mixes were designed according to Department of Environment (DOE) method. The concrete mixes were designed to achieve the target strength $25 \mathrm{MPa}$ at 28 days. The concrete cubes with size $100 \mathrm{~mm}$ x $100 \mathrm{~mm}$ x $100 \mathrm{~mm}$ were prepared. 72 samples of concrete cubes were prepared. Table 1 presents the concrete mix which has been used for this study.

Table 1. Mix Proportions for Concrete Mixes

\begin{tabular}{|c|c|c|c|c|}
\hline Resin & Cement & Water & $\begin{array}{c}\text { Fine } \\
\text { aggrega }\end{array}$ & $\begin{array}{c}\text { Coarse } \\
\text { Aggregates } \\
\left(\mathrm{kg} / \mathrm{m}^{3}\right)\end{array}$ \\
\hline $\begin{array}{c}\text { Percentages } \\
(\%)\end{array}$ & $\left.\mathrm{m}^{3}\right)$ & $\left.\mathrm{m}^{3}\right)$ & $\begin{array}{c}\text { tes }(\mathrm{kg} / \\
\left.\mathrm{m}^{3}\right)\end{array}$ & $\mathrm{NA} / \mathrm{RA}^{*}$ \\
\hline 0 & 360 & 180 & 681 & 1159 \\
\hline 5 & 360 & 180 & 681 & 1101 \\
\hline 10 & 360 & 180 & 681 & 1043 \\
\hline 20 & 360 & 180 & 681 & 927 \\
\hline
\end{tabular}

* NA $=$ Normal Aggregate

$*$ RA $=$ Recycled Aggregate

\subsection{Compressive Strength Test}

This test was conducted according to BS EN 123903:2002. 


\subsection{Water Absorption Test}

This test was conducted according to BS 1881: Part 122 at 28 days age of concrete.

\section{RESULTS AND DISCUSSIONS}

\subsection{Aggregate Impact Value}

Table 2 shows the results of aggregate impact value test. This test was conducted in highway laboratory at UTHM for normal aggregates, recycled aggregates, normal aggregates immersed in epoxy resin and recycled aggregates immersed in epoxy resin.

It is revealed that AIV obtained for RA is higher compared to NA therefore indicating higher strength of NA compared to RA and the results for present study is in agreement with other researchers (Ridzuan et al., 2001 and Limbachiya et al., 2000). According to BS 882:1992, the maximum value of AIV of aggregate for application of heavy-duty floors is $25 \%, 30 \%$ for wearing surfaces and $45 \%$ for other concretes used. Thus, the higher value of AIV for RA indicates that this aggregate is suitable to be used for other concretes purposes. The mortar attached to RA could most probably influence the amount of broken particles size smaller than $2.36 \mathrm{~mm}$ size after the blasting. Thus, this leads into higher value of AIV for RA than that of NA.

Table 2. Aggregate impact value results

\begin{tabular}{|c|c|}
\hline Sample & AIV (\%) \\
\hline NA & 10.9 \\
\hline RA & 20.8 \\
\hline NA immersed in epoxy resin & 8.1 \\
\hline RA immersed in epoxy resin & 13.9 \\
\hline
\end{tabular}

\subsection{Aggregate Crushing Value}

Table 3 shows the results of aggregate crushing value test which were conducted in highway laboratory in UTHM for the normal aggregates, recycled aggregates, normal aggregates immersed in epoxy resin and recycled aggregates immersed in epoxy resin.

From this table, it revealed that the RA was the weakest with the ACV is $31.1 \%$ while the best aggregate was the NA immersed in epoxy resin with ACV is $15.6 \%$. These results showed that the NA strength is higher than that of the RA. In addition, the epoxy resin gave an extra strength to the NA which enhance the strength aggregate. These results illustrated that the NA and the RA immersed in epoxy resin is better compared to the NA and RA without immersed in epoxy resin. According to Neville \& Brooks (2012), the value of ACV influences the compressive strength of concrete. Higher value of $\mathrm{ACV}$, the lower the compressive strength will be and vice verse.

Table 3. Aggregate crushing value results

\begin{tabular}{|c|c|}
\hline Sample & ACV (\%) \\
\hline NA & 16.7 \\
\hline RA & 31.1 \\
\hline $\begin{array}{c}\text { NA immersed in epoxy } \\
\text { resin }\end{array}$ & 15.9 \\
\hline $\begin{array}{c}\text { RA immersed in epoxy } \\
\text { resin }\end{array}$ & 26.4 \\
\hline
\end{tabular}

\subsection{Compressive Strength}

Figure 3 shows the results for the concrete mixtures with different percentages of NA immersed in epoxy resin. The Figure 3 illustrated the relationship between the compressive strength of the concrete mixtures at 7 and 28 days and the increase of the percentage of NA immersed in epoxy resin. The strength of the concrete mixtures started to increase from the mixture which contain $(5 \%)$ of normal aggregates immersed in epoxy resin for both ages. After that, it continues to increase obviously for both ages by increasing the percentage of (NA) immersed in epoxy resin. The highest concrete mixture strength was recorded for the mixture with $(20 \%)$ NA immersed in epoxy resin and it was $39 \mathrm{MPa}$.

These results indicate that the NA immersed in epoxy resin were stronger compared to the NA without immersed in epoxy resin. This result was expected due to the ACV result. It shows that epoxy resin improved the compressive strength of concrete.

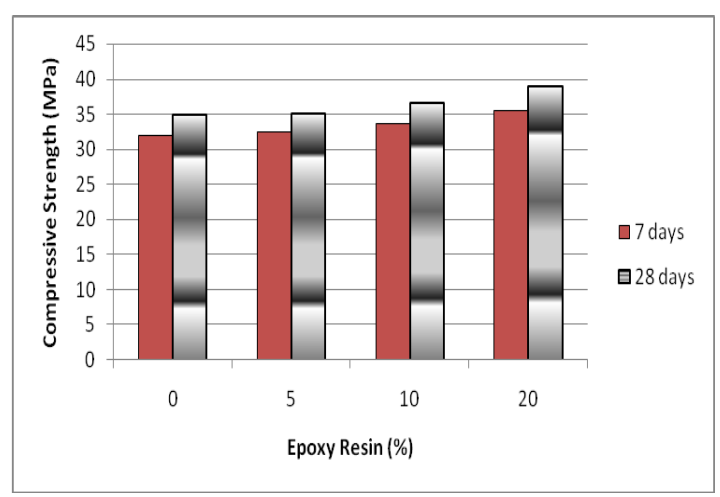

Figure 3. Compressive Strength Result For Normal Aggregate Concrete 
On the other hand, Figure 4 shows the relationship between the compressive strength of the RA concrete immersed with various percentages of epoxy resin for 7 and 28 days. From this figure, it can be seen that the strength of the concrete mixture which contain of RA immersed in epoxy resin slightly increased for both ages. It shows that the strength increases as percentage of epoxy resin increases.

It can be stated that epoxy resin contribute to the better bonding behavior and extra strength towards compressive. The highest concrete mixture strength was recorded for the mixture with $(20 \%)$ RA immersed in epoxy resin and it was $37 \mathrm{MPa}$.

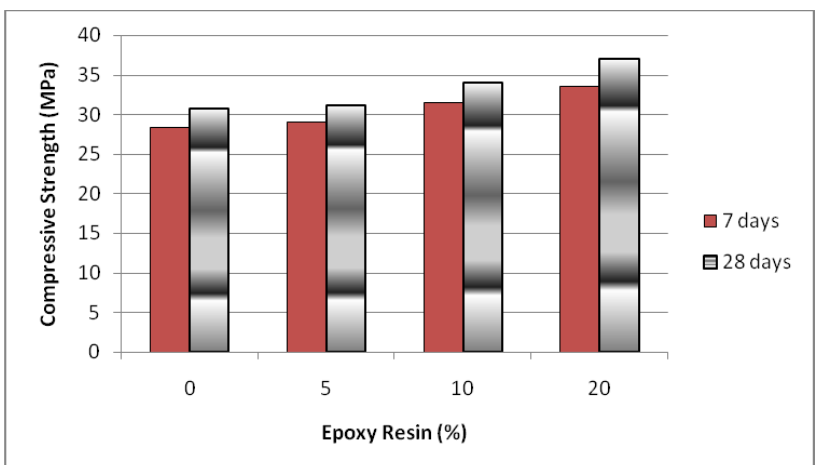

Figure 4. Compressive Strength Result For Recycled Aggregate Concrete

\subsection{Water Absorption}

Table 4 shows water absorption results for all concrete samples. For concrete mixtures used RA showed that the absorption decreased by increasing the percentage of epoxy resin. The recycled aggregates concrete have higher water absorption compared to normal aggregate concrete. This may be due to the mortar that is attached to RA which led into greater porosity and lead into higher water absorption characteristic of RA (Chen et al., 2003). On the other hand, Cakur and Sofyanh (2015) revealed that the high absorption characteristic of RA that developed the higher osmosis pressure. This higher osmosis pressure have a tendency to absorb more water from the surrounding of the samples.

In this study, RA immersed in epoxy resin have lower in water absorption compared to RA without immersed in epoxy resin. As the epoxy resin increases, the water absorption of RA concrete is decreases. However, the concrete with NA without immersed in epoxy resin obtained lower in water absorption compared to NA immersed in epoxy resin. Although the NA without immersed in epoxy resin attain lower in water absorption compared to NA immersed in epoxy resin, as the epoxy resin content is increases the water absoprtion of concrete is decreases.
Table 4. Water absorption results for all concrete mixes

\begin{tabular}{|c|c|c|}
\hline $\begin{array}{c}\text { Percentage of } \\
\text { epoxy resin }\end{array}$ & $\begin{array}{c}\text { Aggregate } \\
\text { type }\end{array}$ & $\begin{array}{c}\text { Absorption } \\
(\%)\end{array}$ \\
\hline \multirow{2}{*}{$0 \%$} & NA & 3.39 \\
\cline { 2 - 3 } & RA & 5.58 \\
\hline \multirow{2}{*}{$5 \%$} & NA & 4.40 \\
\cline { 2 - 3 } $10 \%$ & RA & 5.18 \\
\cline { 2 - 3 } & NA & 4.38 \\
\hline \multirow{2}{*}{$20 \%$} & NA & 4.62 \\
\cline { 2 - 3 } & RA & 4.15 \\
\hline
\end{tabular}

\section{CONCLUSION}

Based on the results of this study, the following conclusions are made:

1) Aggregate impact value for recycled aggregate is higher compared to normal aggregate. Aggregate immersed in epoxy resin obtained lower in impact value than that of aggregate without immersed in epoxy resin.

2) Aggregate crushing value for recycled aggregate is higher than that of normal aggregate. Aggregate immersed in epoxy resin attained lower in crushing value compared to aggregate without immersed in epoxy resin.

3) The compressive strength value increased for all concrete mixtures with the increase of the normal and recycled aggregates immersed in epoxy resin percentage in the concrete mixture.

4) The water absorption of all the concrete mixtures have decreased with the increase of the normal and recycled aggregates immersed in epoxy resin percentage in the concrete mixture.

\section{References}

1. S.H. Adnan, Y.L., Lee, I.A. Rahman, H. Mohd Saman, M.W. Soejose, Compressive strength of recycled aggregate concrete with various percentage of recycled aggregate. Proceeding of National Seminar on Civil Engineering Research (SEPKA 2007), Universiti Teknologi Malaysia, (2007)

2. J.M. Khatib, Properties of concrete incorporating fine recycled aggregate. Cement and Concrete Research, 35 (4), 763-769, (2005) 
3. A.M.Neville, Properties of Concrete, Prentice Hall, (2012)

4. A. Gilat, R. Goldberg and G. Roberts, Strain Rate Sensitivity of Epoxy Resin in Tensile and Shear Loading. J. Aerosp. Eng., 10.1061/(ASCE)08931321(2007)20:2(75), 75-89, (2007)

5. A. Rao, K.N. Jha, \& S. Misra, Use of aggregates from recycled construction and demolition waste in concrete. Resources, Conservation and Recycling, 50(1), 71-81, (2007)

6. F.T. Olorunsogo, \& N. Padayachee, Performance of Recycled Aggregate Concrete Monitored By Durability Indexes. Cement and Concrete Research, 32 (2), 179-185, (2002)

7. A.S. Abdel-Hay, Properties of Recycled Concrete Aggregate Under Different Curing Conditions, Housing and Building National Research Center, http://dx.doi.org/10.1016/j.hbrcj.2015.07.001, (2015)

8. O. Cakir, O.O.Sofyanh, Influence of Silica Fume On Mechanical and Physical Properties of Recycled Aggregate Concrete, Housing and Building National Research Center, 11, 157-166, (2015)

9. Y. Li, X. Liu, J. Yuan, M. Wu, Toughness Improvement of Epoxy Resin Mortar By Incorporation of Ground Calcium Carbonate,Construction and Building Materials, 100, 122-128, (2015)

10. A.R.M. Ridzuan, M.F. Nuruddin, A.B.M. Diah, K.B. Kamarulzaman, (2001). Early Compressive Strength and Drying Shrinkage of Recycled Aggregate Concrete. Proceeding of Seventh International Conference On Concrete Engineering and Technology. Selangor Malaysia, pp. 51-58, (2001)

11. M.C. Limbachiya, T. Leelawat, \& R.K. Dhir. Use of recycled concrete aggregate in high-strength concrete. Materials and Structures, 33, pp. 574-580, (2000). 